\title{
Analytical and Experimental Study of a Naturally Aspirated Indirect Injection 4-Stroke Spark Ignition Engine
}

\author{
Boussad AIT SLIMANE*, Brahim MENACER**, Mostefa BOUCHETARA*** \\ ***Aeronautics and Systems Propelling Laboratory, Department of Mechanical Engineering, University of Sciences and \\ Technology of Oran. BP 1505 El-MNAOUER, USTO 31000 Oran, Algeria \\ **Ecole Superieur en Génie Electrique et Energétique ESGEE Oran, Algeria \\ ***Laboratory of Gas Combustion and Environment Department of Mechanical Engineering, University of Sciences and \\ Technology of Oran. BP 1505 El-MNAOUER, USTO 31000 Oran, Algeria \\ E-mails:*azizmaraval@hotmail.com,**acer.msn@hotmail.fr,***mbouchetara@hotmail.com \\ crossref http://dx.doi.org/10.5755/j01.mech.25.6.23277
}

\section{Introduction}

In addition to experimental investigations, mathematical models of spark-ignition engines are powerful tools for analyzing, predicting and improving engine performance. They are classified into thermodynamic models based on the laws of thermodynamics and dimensional models based on fluid dynamics. In the case of thermodynamic models, there are two categories: single-zone and multizone models. For dimensional models, we have unidimensional and multidimensional models [1-3]. In the case of single zone models, the pressure, temperature and composition of the mixture are assumed to be uniform. These models are used as tools to predict engine performance can take into account mass flows at the cylinder inlet and outlet; but they ignore flame propagation and combustion chamber geometry. Multizone models attempt to solve combustion phenomena in a more physical way than single-zone models [4]. In the two-zone model, there are a burned and an unburned zone. This model allows for a more accurate treatment of the thermodynamic properties of the mixture in the cylinder; burned and unburned gases are considered as distinct thermodynamic systems that are uniform in their composition and condition. However, the geometry of each zone must be followed in order to calculate the heat transfer and the composition of the burned and unburned gases. The two-zone model is used to predict concentrations of combustion products at any engine operating conditions [5], [6]. In this paper, engine simulation is based on a single-zone thermodynamic model developed to characterize each of the engine cycle phases in order to predict the relevant engine performance.

\section{Governing equations of 0-dimensional engine model}

The single zone model used as a basis for the simulation program in the present study is an example of this model type.

\subsection{Mass conservation}

The mass conservation equation applied to the control volume is written as follows, [7]:

$$
\frac{d m_{g}(\theta)}{d \theta}=\frac{d m_{i n}(\theta)}{d \theta}+\frac{d m_{e x h}(\theta)}{d \theta},
$$

where: $\frac{d m_{i n}(\theta)}{d \theta}$ is the mass flow through the intake valve; $\frac{d m_{e x h}(\theta)}{d \theta}$ is the mass flow through the exhaust valve.

\subsection{Ideal gas model}

The ideal gas model expresses the relationship between the mass $m_{g}(\theta)$ in the control volume, its volume $V_{g}(\theta)$, its pressure $p_{g}(\theta)$, and its temperature $T_{g}(\theta)$, [14], [15]:

$$
\begin{aligned}
& \frac{d T_{g}(\theta)}{d \theta}=T_{g}(\theta) \times \\
& \times\left[\frac{1}{p_{g}(\theta)} \frac{d p_{g}(\theta)}{d \theta}+\frac{1}{V_{g}(\theta)} \frac{d V_{g}(\theta)}{d \theta}-\frac{1}{m_{g}(\theta)} \frac{d m_{g}(\theta)}{d \theta}\right] .
\end{aligned}
$$

According to [8], the ideal gas hypothesis is also applied in the formulation of the heat transfer coefficient between the gases and the walls. Indeed, the calculation of the Reynolds number of combustion gases requires the knowledge of their density, which is determined from the ideal gas model. The gas pressure in the cylinder is calculated from the state equation of ideal gases [9]:

$$
\begin{aligned}
& \frac{d p_{g}(\theta)}{d \theta}=\gamma \cdot p_{g}(\theta) \times \\
& \times\left(\frac{1}{m_{g}(\theta)} \frac{d m_{g}(\theta)}{d \theta}-\frac{1}{V_{g}(\theta)} \frac{d V_{g}(\theta)}{d \theta}\right)+ \\
& +\frac{\gamma-1}{V_{g}(\theta)}\left(\frac{d H(\theta)}{d \theta}+\frac{d Q_{w}(\theta)}{d \theta}+\frac{d Q_{f}(\theta)}{d \theta}\right),
\end{aligned}
$$

where: $\gamma$ is the specific heat ratio; $\gamma=1.3$ throughout the cycle [10].

\subsection{Combustion model}

The Vibe-law is generally used for modelling real combustion. The starting point is the dimensionless combustion function [4]: 


$$
x=1-e^{-a \cdot y^{m+1}},
$$

with the related fuel energy $x=Q_{f}(\theta) / Q_{f, t o t}$ and the related combustion duration $y=\frac{\theta-\theta_{i}}{\Delta \theta_{d}}$.

By differentiation of the combustion function $x(y)$ results also the dimensionless combustion rate $d x / d y$ :

$$
\frac{d x}{d y}=a \cdot(m+1) \cdot y^{m} \cdot e^{-a \cdot y^{m+1}} .
$$

In order to determine the Vibe-Function, the following parameters must be known: $Q_{f, t o t}$ is total combustion energy released by each operating cycle; $\theta_{i}$ and $\theta_{e}$ are beginning and end of combustion, or the combustion duration $\Delta \theta_{d}=\theta_{i}-\theta_{e} ; m$ is vibe-Form parameter.

The coefficient $a$ can be set to a constant 6.9; correspondingly, the combustion energy released according to the Eq. (4) at the end of combustion is $99.9 \%$ of the total combustion energy $Q_{f, t o t}$.

The maximal releasable combustion energy $Q_{f, t o t}$ during the combustion of the fuel mass $m_{f}$ can be determined as follows:

$$
Q_{f, t o t}=Q_{f, \max }=m_{f} \times L H V
$$

where: $L H V$ is fuel Lower Heating Value.

The relation (6) is valid for a chemical reaction of fuel and oxygen up to the chemical equilibrium with stoichiometric combustion air ratio $\lambda \geq 1.0$.

In the case of engine operation with $\lambda \prec 1.0$, complete fuel combustion cannot take place so that the heat released per part of fuel mass will be lower. $\mathrm{CO}$ and $\mathrm{H}_{2}$ are produced which cannot be realised due to the oxygen deficiency and remain unused in the exhaust gas.

$$
Q_{f, t o t}=\eta_{c h, c o n v} \times m_{f} \times L H V,
$$

where: $\eta_{\text {ch,conv }}$ is the rate of chemical conversion.

The heat released $d Q_{f}(\theta)$ in the cylinder per crank angle unit $d \theta$ can be written as follows [11]:

$$
\frac{d Q_{f}(\theta)}{d \theta}=\eta_{c h, c o n v} \times m_{f} \times L H V \times \frac{d x(\theta)}{d \theta} .
$$

\subsection{Knockinglimit of the combustion}

Normal combustion in gasoline engines is initiated by spark ignition of the fuel-air mixture at the ignition point. If, for example, the compression ratio is to be increased or the ignition point delayed to "early" in order to increase efficiency, there are limits set by the occurrence of so-called knocking combustion. During knocking combustion, local high pressure and temperature gradients occur, which lead to a greatly increased heat transfer, causing damages to the cylinder head or piston. The so-called knock limit (ignition point at which no knocking occurs at an operating point) is a parameter that significantly limits the allowed operating range of a gasoline engine.

For the engine simulation, it is therefore necessary to be able to predict the knocking tendency at the operating point to be calculated. Franzke [12] has developed a computing method applied to the single zone combustion model. The so-called pre-reaction state of an unburned mixture at the time $\theta$ is defined as follows:

$$
I=\frac{1}{6 \cdot n} \cdot \int_{\theta i n, c}^{\theta} \frac{p_{c}^{a}}{e \frac{b}{T_{u n}}} d \theta,
$$

where: $n$ is engine speed; $p_{c}$ is cylinder pressure; $a, b$ are fuel-specific constants ( $a=1.13 ; b=14930 K) ; T_{u n}$ is temperature of unburned mixture; $\theta_{i n, c}$ is inlet closing time.

The pre-reaction state $I$ can be interpreted as a magnitude of the thermal state or reactivity of the unburned mixture. The temperature in the unburned mixture $T_{u n}$ is calculated according to the following equation (10) from the cylinder pressure $p_{c}(\theta)$, the temperature and pressure at the combustion begin $T_{c o m, b}, p_{c o m, b}$ and the polytropic exponent $n_{c, b}$ for the unburned mixture according to the Eq. (11):

$$
T_{u n}=T_{c o m, b} \cdot\left(\frac{p_{c}(\theta)}{p_{c o m, ~}, b}\right)^{\beta},
$$

with $\beta=\frac{n_{c o m, b}-1}{n_{c o m, b}}$ and $n_{c o m, b}=\left(\frac{\log \frac{p_{c o m, b}}{p_{1}}}{\log \frac{V_{1}}{V_{c o m, ~}}}\right)$,

where: $p_{1}, V_{1}$ are pressure and volume at combustion begin.

The knock limit is characterized by the fact that the critical pre-reaction state triggering the knock is reached when the so-called critical phase of the burning time $\Delta \theta_{c r}$ has elapsed. $\Delta \theta_{c r}$ is determined from the combustion chamber specific constants $k_{c r}$ :

$$
k_{c r}=\Delta \theta_{c r} / \Delta \theta_{c o m b},
$$

where: $\Delta \theta_{c r}$ is critical phase of the burning time; $\Delta \theta_{\text {comb }}$ is total burning time.

With these parameters we can determine the prereaction state at the critical moment $I_{c r}$ :

$$
I_{c r}=\frac{1}{6 . n} \cdot \int_{\theta i n, c}^{\theta c r} \frac{p_{c}^{a}}{e \frac{b}{T_{u n}}} d \theta,
$$

with $\theta_{c r}=\theta_{i n, c}+k_{c r} \cdot \Delta \theta_{c o m b}$. 
The values of $p_{1}, V_{1}, p_{c}(\theta), p_{\text {com. } . b}, V_{\text {com. } . b}, T_{u n}, \Delta \theta_{c r}$ and the quotient $k_{c r}$ must be determined by appropriate evaluation of an engine operating point at the knock limit.

For an arbitrary operating point, the pre-reaction state $I_{a}$ is determined at a given time $\theta_{a}$ by [13]:

$$
I_{e}=\frac{1}{6 . n} \cdot \int_{\theta i n, c}^{\theta c r} \frac{p_{c}^{a}}{e \frac{b}{T_{u n}}} d \theta
$$

with $\theta_{e}=\theta_{i n, c}+k_{c r} . \Delta \theta_{\text {comb }}$.

So, a differentiation can be made between normal and knocking combustion according to the following criteria [12]:

$$
\begin{aligned}
& I_{e} \prec I_{c r}: \text { normal combustion, } \\
& I_{e}=I_{c r}: \text { knock limit, } \\
& I_{e} \succ I_{c r}: \text { knocking combustion. }
\end{aligned}
$$

Due to the relative complex analytical and experimental investigations for the mathematical determination of the knock limit, the following simplified criterium is used in this study to estimate the knock tendency: If two operating points to be compared have the same pre-reaction state $I_{e}$ at the given time, it is assumed that the knock tendency is identical. This corresponds to a qualitative evaluation of the knocking tendency without explicit calculation of the knocking limit, which would require a determination of the constants $a, b$ and $k_{c r}$ in the engine test bench.

\subsection{Heat transfer in the cylinder}

The wall heat flow across the limits of the cylinder system or the inlet and outlet flow ducts in the cylinder head is calculated according to Newton's equation for convective heat transfer [14]:

$$
\frac{d Q_{w}(\theta)}{d \theta}=\frac{1}{6 . n} \times h(\theta) \times A_{w}(\theta) \times\left(T_{g}(\theta)-T_{w}\right),
$$

where: $d Q_{w}(\theta) / d \theta$ is instantaneous convective heat transfer rate from in-cylinder gas to cylinder wall; $A_{w}(\theta)$ is instantaneous wall area; $T_{g}(\theta)$ is instantaneous average working gas temperature; $T_{w}$ is wall temperature averaged temporally and locally over a work cycle; $h(\theta)$ is instantaneous local mean heat transfer coefficient; $n$ is engine speed.

The instantaneous local mean heat transfer coefficient $h(\theta)$ for the cylinder is given by the Woschni correlation [15]:

$$
h(\theta)=130 \times D^{-0.2} \times T_{g}^{-0.53} \times p_{g}^{0.8} \times v_{g}^{0.8} .
$$

The average cylinder gas velocity $v_{g}$ is calculated as:

$$
v_{g}=k_{1} \cdot c_{m}+k_{2} \cdot\left(\frac{V_{d} \cdot T_{1}}{p_{1} \cdot V_{1}}\right)\left[p_{g}-p_{1} \cdot\left(\frac{v_{1}}{v_{g}}\right)^{k}\right],
$$

where: $c_{m}$ is the mean piston speed; $V_{d}$ is the displacement volume; $p_{1}$ is the reference pressure; $T_{1}$ is the reference temperature and $V_{1}$ is the reference volume.

The coefficients $k_{1}$ and $k_{2}$ depend on the engine cycle stroke. For the gas exchange phase, $k_{1}$ is equal to about 6.18 and to about 2.28 for compression, combustion and expansion. The coefficient $k_{2}$ is equal to $3.24 \times 10^{-3}$ for combustion and expansion periods and to zero for the other engine cycle strokes [16].

For the inlet and outlet pipes in the cylinder head, the heat transfers between the working gas and the wall must also be taken into account, otherwise the heating of the fresh gas mixture on the inlet side would be neglected, so that the calculated filling ratio would be too high. On the exhaust side, exhaust gas temperatures would be too high without taking the wall heat transfer in the exhaust pipe into account, which would result in an error in the power calculation of the turbine. The wall heat transfer coefficient is calculated according to Zapf's approach [17].

For the inlet canal, the heat transfer coefficient is calculated as follows:

$$
h_{i, c}=2.1515 \times\left(1-0.765 \cdot \frac{e_{v, i}}{d_{v, o}}\right) \times \dot{m}_{t}^{0.68} \times T_{1}^{0.28} \times D_{i}^{-1.68},
$$

and for the outlet canal:

$$
h_{o, c}=1.79102 \times\left(1-0.770 . \frac{e_{o, v}}{d_{o, v}}\right) \times \dot{m}_{o}^{0.5} \times T_{1}^{0.41} \times D_{o}^{-1.5},
$$

where: $h_{i, c} ; h_{o, c}$ are actual valve lift; $\dot{m}$ is actual mass flow; $T_{1}$ is actual gas temperature at inlet canal; $d_{v}$ is inner valve seat diameter; $D_{i}, D_{o}$ are average canal diameter.

\section{Main engine performanceparameters}

\subsection{Effective and indicated power}

The effective power bpower for 4-stroke engine is [17]:

$$
\text { bpower }=\text { bmep } \times V_{d} \times N_{c y l s} \times N / 2,
$$

where: $N_{c y s}$ is cylinder number; $N$ is engine speed and bmep is brake mean effective pressure.

\subsection{Effective torque}

The effective torque is given by:

$$
\text { torque }=\text { bpower } /(2 \pi N) .
$$

\subsection{Effective efficiency}

The effective efficiency $R_{\text {ef }}$ is given by [18]:

$$
R_{\text {eff }}=W_{d} / Q_{\text {comb }},
$$


where: $Q_{\text {comb }}$ is heat release during combustion and $W_{d}$ is work done.

\subsection{Specific fuel consumption}

The specific fuel consumption $b s f c[\mathrm{~g} / \mathrm{kWh}]$ is equal to:

$$
\text { bsfc }=\dot{m_{f}} / \text { bpower } .
$$

\section{Description of the used engine test bench}

Fig. 1 shows the engine test bench from the German manufacturer Weinlich Steuerung GmbH equipped with the engine, type Ford ZSG 216, spark ignition 4-stroke, 4-cylinder in line DOHC and with a sequential multi-point injection with PCM control unit. The test bench comprises the braking dynamometer based on an air-cooled eddy current brake, the measuring unit for the speed and the torque, the evaluation, display and control unit including the MP calculator, a controller for the eddy current brake and power supply units. We have a manual operating unit for controlling the eddy current brake, a precision balance for gravimetric determination of the specific fuel consumption, an air consumption metering unit and equipment for the air condition. To the engine is mounted a measuring turbine for the coolant flow, two thermocouples for the coolant temperature, one thermocouple for the exhaust gas temperature, a pressure transducer and one thermocouple for the state of the lubrification oil. The MP calculator evaluates the engine speed and torque signals supplied by the braking and measuring unit, information from the balance weighing the fuel tank, signals from the further measuring equipment mentioned above, and from an indicator control additionally contained in the control unit. It calculates engine power, work and specific fuel consumption. It indicates speed, torque, power, work, specific fuel consumption and some operating conditions. It sends every information to the PC and can be used for controlling the eddy current brake in the braking and measuring unit. The MP calculator sends information to the serial input RS 232 of the PC und the balance inputs the fuel weight into the MP calculator. The Table 1 gives the technical data of test SI engine Ford, type ZSG 416, 1.61, 74 $\mathrm{kW}$.

\section{Configuration of the developed engine simulation program}

In order to validate the results of the experimental tests, a numerical simulation study was carried out using an engine cycle simulation program developed in FORTRAN language. The GT-Power engine software, which is an engine simulation and analysis tool, is used in this study only to compare the results obtained using the simulation program developed. The numerical simulation is applied to a four-stroke spark ignition engine with four cylinders and fuel injection. The characteristics of this engine are presented in Table 1. The engine cycle simulation program developed in FORTRAN language, which is a program for evaluating the thermodynamic parameters and performance of 4-stroke gasoline engines with indirect injection, is based on the single-zone combustion model described in paragraph 2, while taking into account the knock phenomena. It includes a main program as an organizational routine and several subprograms. The simulation model developed with the GT-Power engine software is shown in Fig. 2.

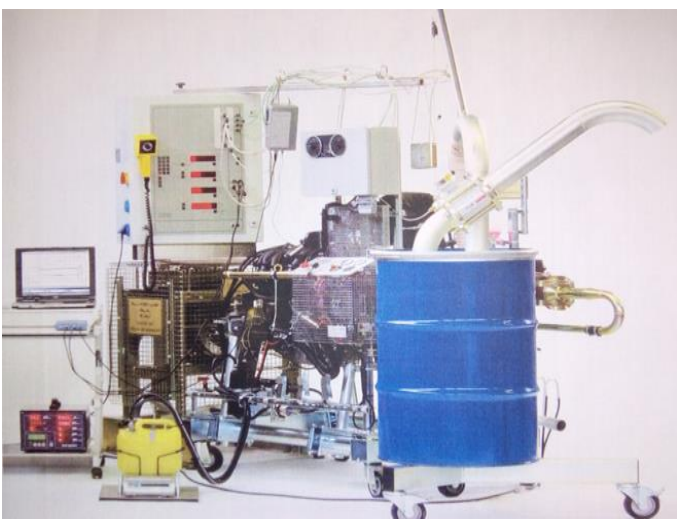

Fig. 1 Test bench of the German manufacturer Weinlich Steuerung GmbH equipped with Ford ZSG 216 gasoline engine

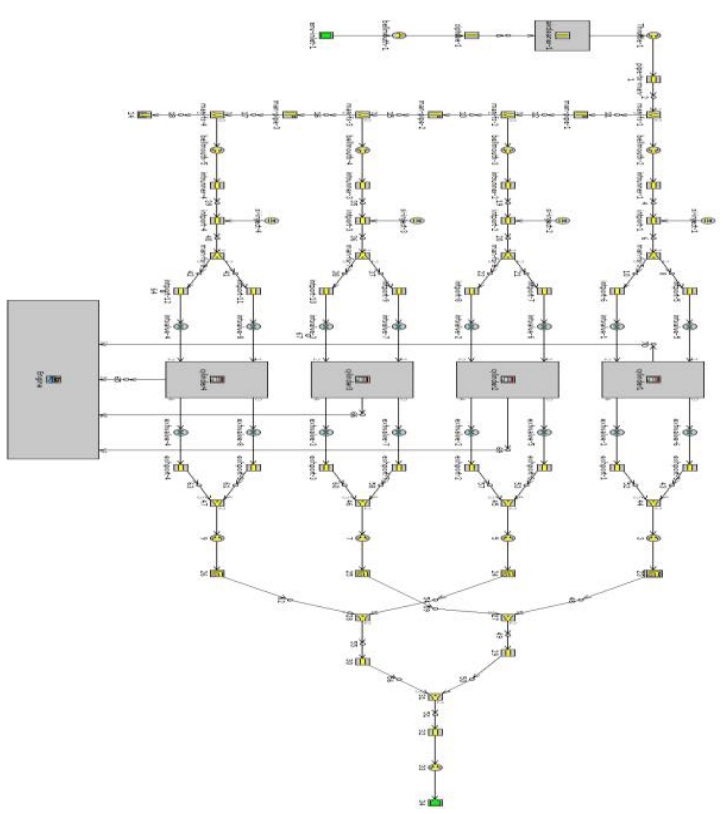

Fig. 2 The ZSG 416 Ford engine model with GT-Power software

Table 1

Technical data of test SI engine ZSG 216 Ford

\begin{tabular}{|c|c|}
\hline Engine data & Values \\
\hline Type & $\begin{array}{c}\text { ZSG 216 Ford } \\
\text { Spark ignition 4-stroke, } \\
\text { 4-cylinder in line DOHC }\end{array}$ \\
\hline Engine management & $\begin{array}{l}\text { Sequential multi-point injec- } \\
\text { tion with PCM control unit }\end{array}$ \\
\hline Displacement, $\mathrm{dm}^{3}$ & 1595 \\
\hline Bore, $\mathrm{mm}$ & 79 \\
\hline Stroke, $\mathrm{mm}$ & 81.4 \\
\hline Connecting Rod Length, mm & 137 \\
\hline Compression Ratio & $11,0: 1$ \\
\hline Number of Cylinders & 4 \\
\hline Intake Valve Opens, deg & $20 \mathrm{BTDC}$ \\
\hline Intake Valve Closes, deg & $70 \mathrm{ABDC}$ \\
\hline Exhaust Valve Opens, deg & $50 \mathrm{BBDC}$ \\
\hline Exhaust Valve Closes, deg & 30 ATDC \\
\hline
\end{tabular}


Continuation of Table 1

\begin{tabular}{|l|c|}
\hline \multicolumn{1}{|c|}{ Engine data } & Values \\
\hline Number of strokes & 4 \\
\hline Maximum Power output, $\mathrm{kW}$ & 74 at 6000 rpm \\
\hline Maximum Torque output, $\mathrm{Nm}$ & 146 at 4000 rpm \\
\hline Average dry weight, $\mathrm{kg}$ & 81 \\
\hline Application & A (automotive applications) \\
\hline Atmospheric Pressure, $\mathrm{Pa}$ & 101325 \\
\hline Atmospheric Temperature, $\mathrm{K}$ & 298 \\
\hline
\end{tabular}

\section{Results and discussions}

\subsection{Brake torque and brake power at full load}

Fig. 3 shows respectively the results obtained experimentally, with the GT-Power software and the program developed in FORTRAN language of the brake power and brake torque at full load versus engine speed for a compression ratio of $11: 1$, a cylinder wall temperature of $450 \mathrm{~K}$, an

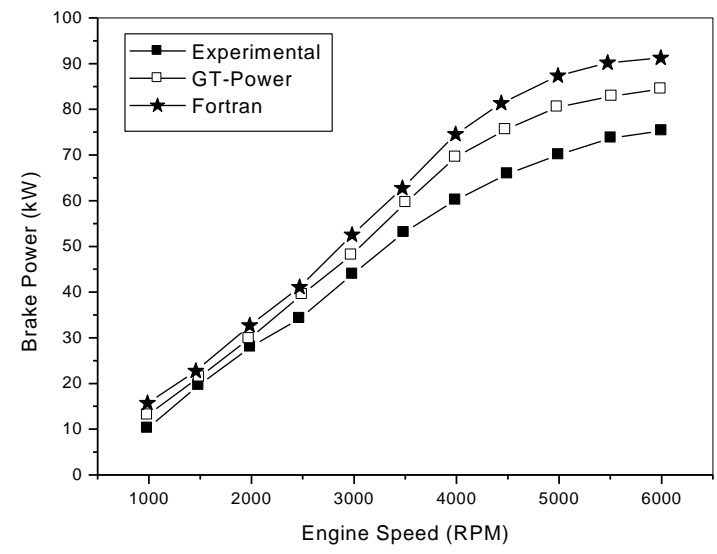

a

Fig. 3 Brake power (a) and brake torque (b) versus engine speed at full load

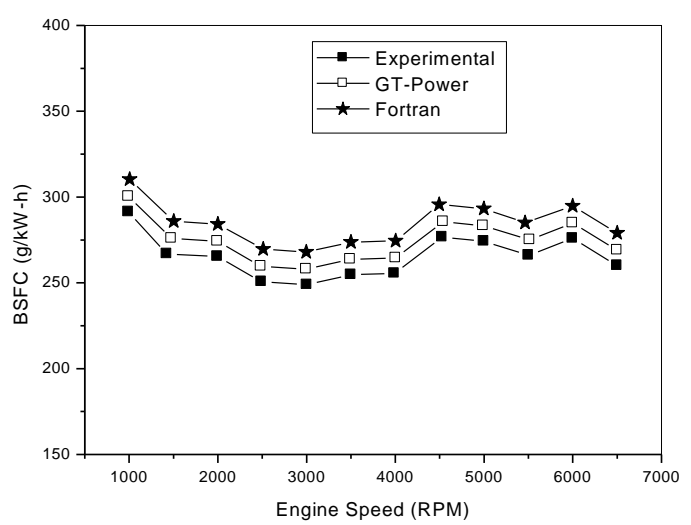

Fig. 4 Specific fuel consumption versus engine speed at full load

\subsection{Influence of the cylinder bore on the engine performance}

The effect of the cylinder bore on braking power and efficiency is shown in Fig. 5. In the evaluation of the graphs in Fig. 5, two characteristic operating points must be distinguished: the first refers to maximum efficiency and the second to maximum power.

Fig. 5 shows that engine performance improves with increasing cylinder diameter. For a given power at low ignition advance of $15^{\circ} \mathrm{BTDC}$ and $F / A$ Ratio of 0,9 . The effective power increases with engine speed up to a maximum speed of $6000 \mathrm{rpm}$. The value of the maximum effective power obtained experimentally is equal to that provided by the manufacturer (Table 1). It can be clearly seen that there is a good match between the experimental results and those obtained using the GT-Power software and the program developed. Either for effective engine torque or effective power, the difference between the experimental results and those obtained with the developed program does not exceed 5\%. Fig. 4 presents the specific fuel consumption at full load as function of engine speed, obtained experimentally, with the GT-Power software and with the program developed in FORTRAN language. It should be noted that independently of the fuel consumption evaluation procedure, the minimum specific fuel consumption range is between 2500 and $4000 \mathrm{rpm}$. The gap between the experimental and simulated results does not exceed $7 \%$.

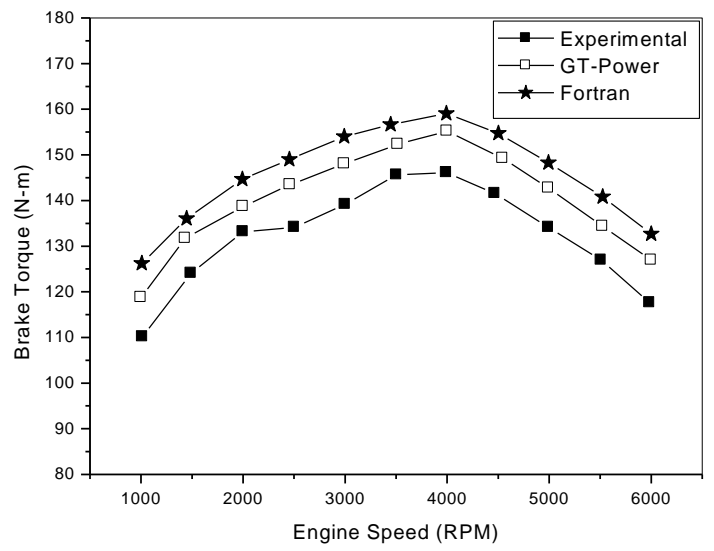

engine speeds, it is recommended to use a large diameter cylinder, which allows a better efficiency. For example, if the cylinder bore is increased by $10 \mathrm{~mm}$, the efficiency increases by $5 \%$. For a given performance at high engine speeds, the cylinder bore provides greater braking power. For a given efficiency of $25 \%$, the increase in the cylinder bore by $10 \mathrm{~mm}$ will result in a $7 \%$ higher braking power. Qualitatively, there is a good agreement between the results obtained with the GT-Power software and the program developed in FORTRAN language.

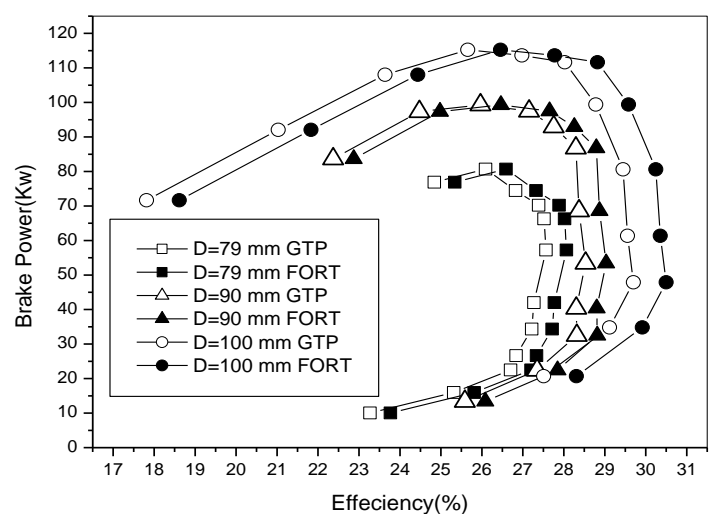

Fig. 5 Influence of cylinder bore on engine efficiency and brake power at full load 


\subsection{Influence of the compression ratio}

Fig. 6 shows the influence of the compression ratio on power and efficiency at full load. With the increase of the compression ratio, we have an increase in maximum power and efficiency values. For a power of $55 \mathrm{~kW}$ and an increase in the compression ratio of $10.5 \%$ (from $11: 1$ to $13: 1$ ) will improve the efficiency by $7.5 \%$. For an efficiency of $27 \%$ and $10.5 \%$ compression ratio gain, the power increases by $4.5 \%$. This means that the effect of the compression ratio on efficiency is greater than on the power.

\subsection{Influence of the fuel/air ratio}

As shown the Fig. 7, the fuel/air ratio has a more significant effect on optimal efficiency than on maximum

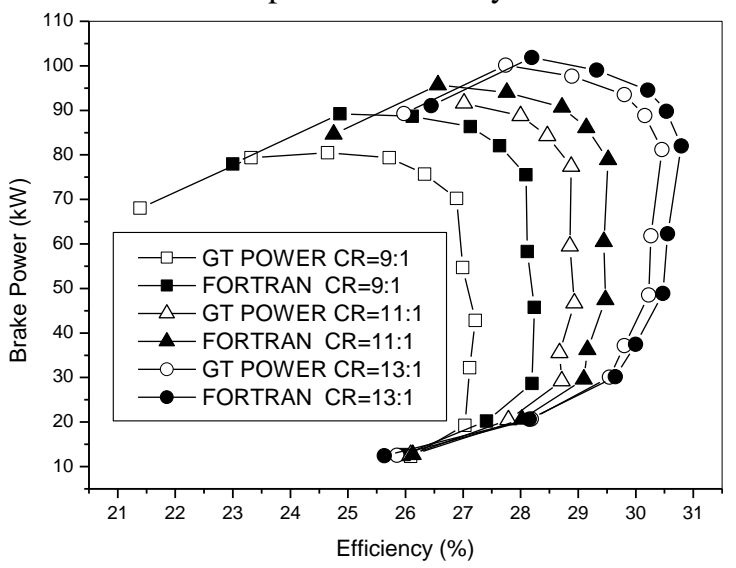

Fig. 6 Effect of compression ratio on the engine power and efficiency at full load

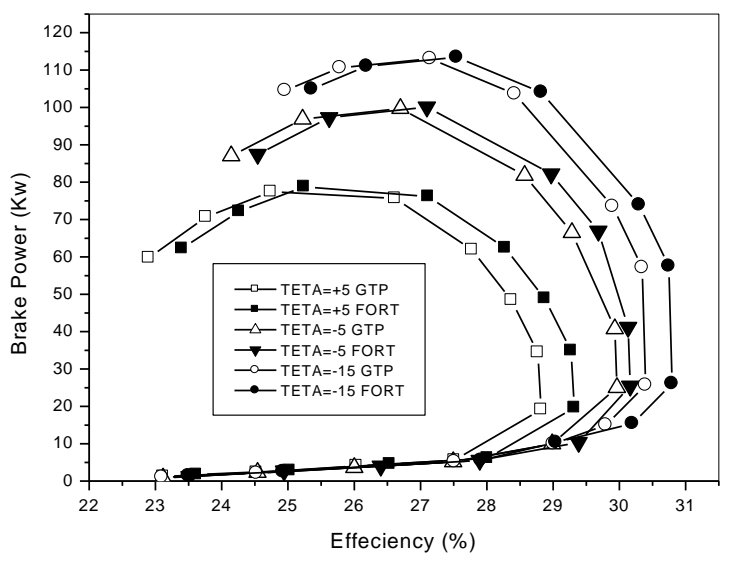

Fig. 8 Effect of ignition begin on the brake power and efficiency

\section{Conclusion}

The main purpose of this contribution is first of all to validate the simulation program of a four-stroke gasoline engine developed in FORTRAN language with experimental tests and GT-Power software and also to predict engine operating parameters such as brake power, brake torque, specific fuel consumption. Comparison of theoretical and experimental performance shows that the power deviation was $\pm 3 \%$ and the torque deviation $\pm 6 \%$, while the BSFC difference was $\pm 10 \%$. A theoretical and experimental evaluation was then carried out to analyze the effect of five power. For a given power of $55 \mathrm{~kW}$ and a fuel/air ratio variation of $12 \%$ (from 1.0 to 1.1 ), the maximum efficiency increases by about $21 \%$. For a given efficiency of $27 \%$ and the same variation in fuel/air ratio, the maximum power increases by only $5 \%$.

\subsection{Influence of ignition begin}

As with the compression ratio, the ignition start point is a very important parameter in optimizing of engine performance. With an initial ignition advance of $15^{\circ}$ compared to TDC, the maximum power increases by $10 \%$, while with an initial ignition delay of $5^{\circ}$ compared to TDC, the maximum power decreases by $18 \%$, Fig. 8 . When adjusting the ignition delay, the knock problem must be avoided.

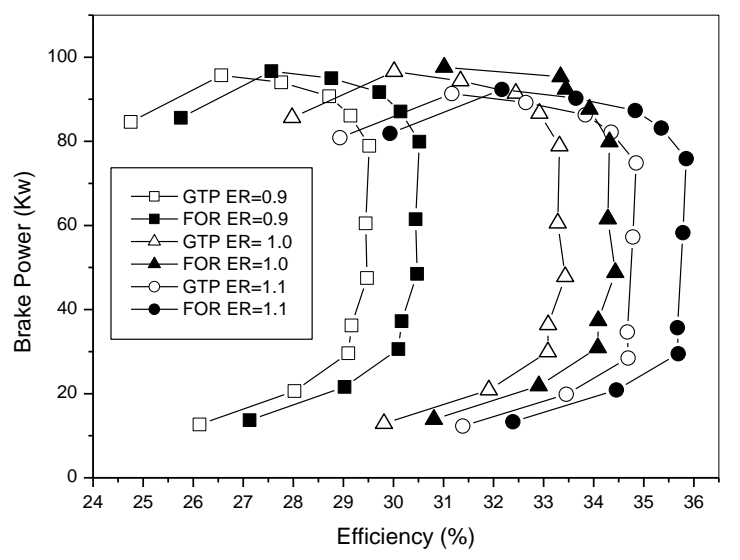

Fig. 7 Influence of fuel/air ratio on the brake power and efficiency

selected engine data, namely cylinder wall temperature, cylinder bore, compression ratio, ignition start and fuel/air ratio on the performance of the investigated gasoline engine. From the comparison of the results obtained, it might be able to conclude, that except for cylinder wall temperature, all other chosen parameters have a significant influence on the gasoline engine performance. It has been found that engine performance improves by reasonably increasing the chosen parameters:

- For example, by increasing the cylinder bore by $10 \mathrm{~mm}$, the efficiency can be improved by $5 \%$.

- By increasing the compression ratio by about $10 \%$, the efficiency can be improved by $7.5 \%$ for a given power.

- A $12 \%$ increase in the air/fuel ratio can lead to a $21 \%$ improvement in efficiency for a given power.

- With an initial ignition advance of $15^{\circ}$ compared to TDC, the maximum power increases by $10 \%$.

Although in the computing program developed, we used only the single-zone combustion model, the results obtained proved to be satisfactory. In order to assist in the future development of gasoline engines, it would be judicious, for example, to test other combustion models with better predictive capabilities. With a multi-zone combustion model instead of a single- zone model, we will be able to predict the engine's behavior in terms of engine performance and pollutant emissions. Engine data must also be concentrated on other relevant parameters such as valve 
timing, swirl/tumble effect, combustion fraction and intake air temperature.

\section{References}

1. Kopac, M.; et al. 2005. Determination of optimum speed of an internal combustion engine by exergy analysis, International Journal of Exergy 2: 40-54. https://doi.org/ DOI: 10.1504/IJEX.2005.006432.

2. Benson, R.; et al. 1982. The Thermodynamics and Gas Dynamics of Internal Combustion Engines: Clarendon Press, Oxford. https://trove.nla.gov.au/version/45485985.

3. Abd Alla, G. H. 2002. Computer simulation of a fourstroke spark ignition engine: En. Convers, Mng. 43: 1043 - 1061. https://doi.org/ doi:10.1016/j.fuel.2010.07.021.

4. Heywood, J. B. 1988. Internal combustion engine fundamentals. McGraw-Hill, New York. http://dx.doi.org/10.1016/S0082-0784(75)80383-3.

5. Zareei, J.; Kakaee, A. H. 2013. Study and the effects of ignition timing on gasoline engine performance and emissions, European Transport Research Review 5(2): 109-116. https://doi.org/ DOI 10.1007/s12544-013-0099-8.

6. Ubwa, S. T.; et. al. 2014. Determination of performance characteristics of petrol/bio-ethanol blends for spark Ignition (SI) Engines, International Journal of Renewable Energy Research (IJRER) 4: 73-76. https://doi.org/ DOI: 10.9790/1684-1602010106.

7. Ferguson, C. R. 1985. Internal combustion engine, applied Thermosciences. New York, NY: Wiley. https://doi.org/www.osti.gov/biblio/5822574.

8. Gulder, O. 1984. Correlations of laminar combustion data for alternative S.I. engine fuels. SAE paper no. 841000, 1-23. https://doi.org/ /10.4271/841000.

9. Hirani, J. V.; et. al. 2013. Effect of injection timing and compression ratio on the performance of LPG- home biodiesel dual fuel engine, International Journal of Emerging Technology and Advanced Engineering 3: 16-24. https://doi.org/10.1177/0957650912470907.

10. Yousufuddin, S.; Mehdi, S. N. 2008. Effect of ignition timing, equivalence ratio, and compression ratio on the performance and emission characteristics of a variable compression ratio SI engine using ethanol unleaded gasoline blends, International Journal of Engineering Transactions B: Applications 21(1): 97-106. https://doi.org/10.1063/1.5075549.

11. Menacer, B.; Bouchetara, M. 2015. Computational thermodynamic of a turbocharged direct injection diesel engine, Mechanika 21(1): 40-50. http://dx.doi.org/10.5755/j01.mech.21.1.8690.

12. Franzke, D. E. 1981. Beitrag zur Ermittlung eines Klopfkriteriums der ottomotorischen Verbrennung und zur Vorausberechnung der Klopfgrenze. Thesis TU München. https://doi.org/10.1007/BF03226689.

13. Keck, J. C. 1982. Turbulent flame structure and speed in spark-ignition engines, In 19th Int. Symp. Combustion 1451-1466. https://doi.org/10.1016/S0082-0784(82)80322-6.
14. Ashish, M. A. et al. 2014. Effect of Compression Ratio and Spark Timing on Performance and Emission of Dedicated 4-Stroke S.I Engine Fueled With LPG. https://doi.org/10.1007/s12544-013-0099-8.

15. Zheng, J. J. et al. 2009. Effect of the compression ratio on the performance and combustion of a natural- gas direct-injection engine, Proceedings of the institution of mechanical engineers, part d: Journal of automobile engineering 223:85-98. http://dx.doi.org/10.1016/j.ijhydene.2015.02.058.

16. Korakianitiset T. et. al. 2011. Natural-gas fueled sparkignition (SI) and compression-ignition (CI) engine performance and emissions, Progress in Energy and Combustion Science 37: 89-112. https://doi.org/doi:10.1016/j.pecs.2010.04.002.

17. Zapf, H. 1969. Beitrag zur Untersuchung des Warmeübergangs während des Ladungswechsels im viertaktDieselmotor, MTZ 30 (1969)12, pp 461-465. https://doi.org/10.1007/978-3-540-72165-9_7.

18. Ferentiet, I. et al. 2014. Research of some operating parameters and the emissions level variation in a spark ignited engine through on-board investigation methods in different loading conditions, Open Eng. 4(2):192- 208. https://doi.org/10.4271/2011-01-0143.

\section{B, Ait Slimane, B. Menacer, M. Bouchetara}

\section{ANALYTICAL AND EXPERIMENTAL STUDY OF A NATURALLY ASPIRATED INDIRECT INJECTION 4-STROKE SPARK IGNITION ENGINE}

S u m m a r y

One of the objectives of this study is to elaborate an engine cycle simulation program in FORTRAN language to analyze the influence of operating parameters on the performance (the effective power, torque and specific fuel consumption) of a four-stroke gasoline engine (Ford ZSG 416 gasoline engine) for different engine operating parameters. The GT-Power engine simulation software was used to compare the results obtained with the developed computer program and to improve it. In this program, a single-zone thermodynamic model was considered, which describes each phase of the engine cycle. In order to validate the developed program, a comparison of the experimental results with those obtained using GT-Power software was carried out. Examining the experimental results and those obtained with the developed program, it was observed that the power difference was in the order of $\pm 3 \%$, the torque difference was $\pm 6 \%$, while the BSFC difference was about $\pm 10 \%$. It has been noted that the most significant parameters in improving the performance of the gasoline engine are the compression ratio, the fuel/air ratio, the engine geometry and the ignition begin. The variation of these parameters was not arbitrary, the knock criteria, in other words, the achievement of normal combustion were taken into account.

Keyword: engine simulation, spark ignition engine, simulation models, combustion models, knocking limit, engine performance, GT-Power software.

Received April 23, 2019 Accepted November 21, 2019 